\title{
Martensitic transformation temperatures and microstructural features of FeMnCr Alloys
}

\author{
H. E. Troiani ${ }^{1,2, \text { a }}$, M. Sade ${ }^{1,2}$, G. Bertolino ${ }^{1,2}$ and A. Baruj ${ }^{1,2}$ \\ ${ }^{1}$ Centro Atómico Bariloche and Instituto Balseiro, 8400 S. C. Bariloche, Argentina. \\ 2 CONICET, Argentina.
}

\begin{abstract}
FeMn based alloys are a low cost alternative to traditional SMAs due to their convenient one-way shape memory effect. While alloy systems containing several elements have received considerable attention along the last few years, namely FeMnSiCr, FeMnSiCrNi and modifications of these two containing precipitates, there is still scarce information about some of the related ternary systems. An important example is the FeMnCr system. Information about phase stability and transformation temperatures in this ternary system would be useful as input data for higher order alloy design. We present experimental $\mathrm{fcc} / \mathrm{hcp}$ martensitic transformation temperatures of selected $\mathrm{FeMnCr}$ alloys measured by means of dilatometry and electrical resistivity. We have found that these transformation temperatures suffer an evolution when samples are thermally cycled, up to an asymptotic state. In the case of the studied samples, this asymptotic state is reached after a small number of cycles $(n<5)$. TEM observations aimed at elucidating the origin of this behavior found two main microstructural features: 1) the presence of very small precipitates in the alloy matrix, and 2) a tendency to form mono-oriented martensite inside each grain.
\end{abstract}

\section{Introduction}

Fe-Mn-based alloys have been the subject of recent studies in connection with their one-way shape-memory effect (SME) [1-3]. The SME in these alloys is related to a fcc/hcp martensitic transformation. Under favourable conditions, stress induced hcp phase reversibly transforms to fcc upon heating, reverting the imposed shape change [4-5]. In particular, ternary (Fe-Mn-Si) and higher-order alloys based on the Fe-Mn system display a complete SME. In addition, Fe-Mn-Si-based shape memory alloys (SMAs) are machinable, easily weldable and of relatively low cost. As a consequence, they are alternative for large-scale applications such as pipe joints [6], bolts and the composite reinforcement [7].

Fe-Mn-Si-based SMAs usually contain between 15 and $30 \mathrm{wt} . \% \mathrm{Mn}$ in order to stabilize the fcc to hep transformation, and up to $6 \mathrm{wt} . \% \mathrm{Si}$ to control the stacking fault energy and antiferromagnetic ordering temperature $(\mathrm{TN})$ of the austenitic structure. Higher order alloys usually contain $\mathrm{Cr}$ and $\mathrm{Ni}$. The addition of $\mathrm{Cr}$, usually between 5-9 wt.\%, improves the material's corrosion resistance. When $\mathrm{Cr}$ content is above 7 wt.\%, the alloy is prone to form the $\mathrm{Fe}-\mathrm{Cr}$ sigma phase $\left(\sigma_{\mathrm{Fe}-\mathrm{Cr}}\right)$ which results in material embrittlement [8]. In order to avert this possibility, $\mathrm{Ni}$ is added to prevent sigma phase formation, in a similar way as it is done with stainless steels [9]. As a result, alloys useful for a applications easily end up containing five or more elements.

There is a set of properties which increase the effectiveness of the SME:

- The martensite start temperature $\left(\mathrm{M}_{\mathrm{s}}\right.$, fcc to hcp) should be below, and close to, room temperature. Then, martensite will only be induced during the straining step, thus maximizing the SME.

- The austenite start temperature $\left(\mathrm{A}_{\mathrm{s}}\right.$, hcp to fcc) should be higher than $60{ }^{\circ} \mathrm{C}$. Then, a pre-strained element can be handled and positioned before inducing shape recovery without the need of keeping it cool as it happens, for example, with normal NiTi parts.

- The Neél temperature $\left(\mathrm{T}_{\mathrm{N}}\right)$ for the fcc phase should be lower than room temperature in order to favor hcp introduction by straining.

- Stacking faults in the fcc phase act as nucleation sites for the hcp phase. Then, stacking fault energy of the fcc phase should be low, in order to allow an easy nucleation of the hcp phase.

In the Fe-Mn-based alloy family, chemical composition can be fine tuned to approach to this set of properties. However, selecting the right combination of elements in order to obtain all these properties in a multicomponent alloy is not an easy task. Methods based on computational alloy design are being applied with some degree of success. One of these methods, based in the so-called CALPHAD approach, requires of thermodynamic information about the phases of interest in, at least, the intervening pure elements, and their binary and ternary combinations. Then, there is an additional problem regarding Fe-Mn-based SMAs. The

a e-mail: troianidcab. cnea.gov.ar

This is an Open Access article distributed under the terms of the Creative Commons Attribution-Noncommercial License (http://creativecommons.org/licenses/by-nc/3.0/), which permits unrestricted use, distribution, and reproduction in any noncommercial medium, provided the original work is properly cited. 
phases of interest, fcc and hcp, are metastable at room temperature. Although the fcc/hcp metastable equilibrium has been studied in the binary Fe-Mn, Fe-Si and $\mathrm{Fe}-\mathrm{Cr}$ and ternary Fe-Mn-Si systems, the information concerning other Fe-Mn-based ternary systems involved (namely Fe-Mn-Cr and Fe-Mn-Ni) is scarce [10].

In this work, we present an experimental study of the fcc/hcp martensitic transformation in the Fe-MnCr system. We have also performed transmission electron microscopy (TEM) observations of the microstructure of these alloys in order to identify their characteristic features.

\section{Experimental}

Fe-Mn-Cr alloys were arc melted from the pure metals several times under Ar atmosphere. The resulting alloys (buttons of approximately $15 \mathrm{~g}$ ) were heat-treated in quartz capsules under Ar atmosphere for 48 hours at $1273 \mathrm{~K}$, and water quenched. Samples for dilatometry $\left(2 \times 2 \times 15 \mathrm{~mm}^{3}\right)$ and electrical resistivity measurements $\left(1 \times 5 \times 12 \mathrm{~mm}^{3}\right)$ were spark cut from the buttons. All samples were polished, individually encapsulated into quartz tubes under Ar atmosphere, annealed for $1 \mathrm{~h}$ at $1273 \mathrm{~K}$, and water quenched by breaking the capsules. The composition of each alloy studied in this work was determined by electron beam microanalysis using an energy dispersive spectrometer (EDS) and the pure elements as standards. The transformation temperatures were determined by using either a dilatometer or an electrical resistivity equipment, both designed and built in our laboratory. In all cases, a spot welded Chromel-Alumel thermocouple was placed on the surface of the samples in order to accurately measure the temperature.

Samples for transmission electron microscopy (TEM) observations were prepared directly from electrical resistivity samples. The $1 \mathrm{~mm}$ thick slices were first thinned down to $0.2 \mathrm{~mm}$ by applying a chemical polishing procedure. Then, discs of approximately $3 \mathrm{~mm}$ in diameter were cut, again by applying a suitable chemical solution to the thin slices. As a result, these TEM samples were never mechanically polished, ensuring in this way the observation of defects or phases solely introduced during thermal cycling. Finally, the discs were electropolished using a double jet with an acetic:perchloric 95:5 solution. The samples were observed in a Philips CM200 TEM with an accelerating voltage of $200 \mathrm{kV}$ and ultratwin objective lens.

\section{Results}

\subsection{Martensitic transformation temperatures}

Martensitic transformation temperatures of $\mathrm{FeMnCr}$ alloys were determined either by electrical resistivity or dilatometry. In general, a good agreement has been obtained between electrical resistivity and dilatometry measurements for different samples of the same alloy.

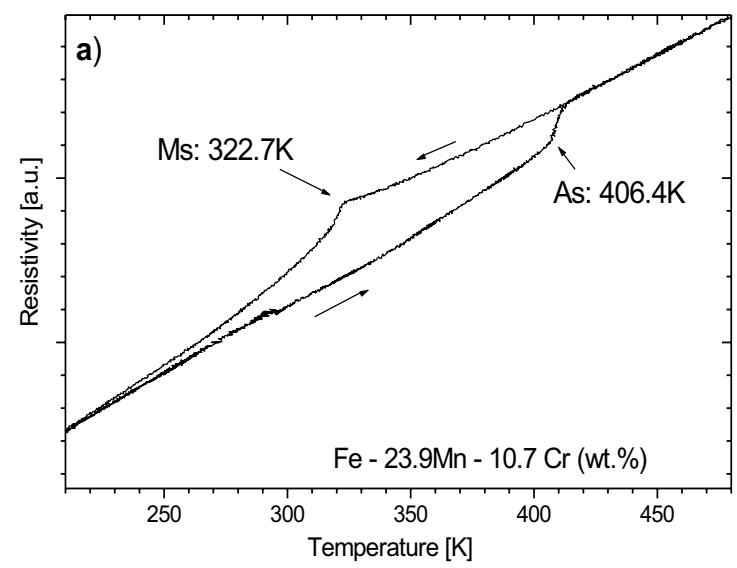

(a)

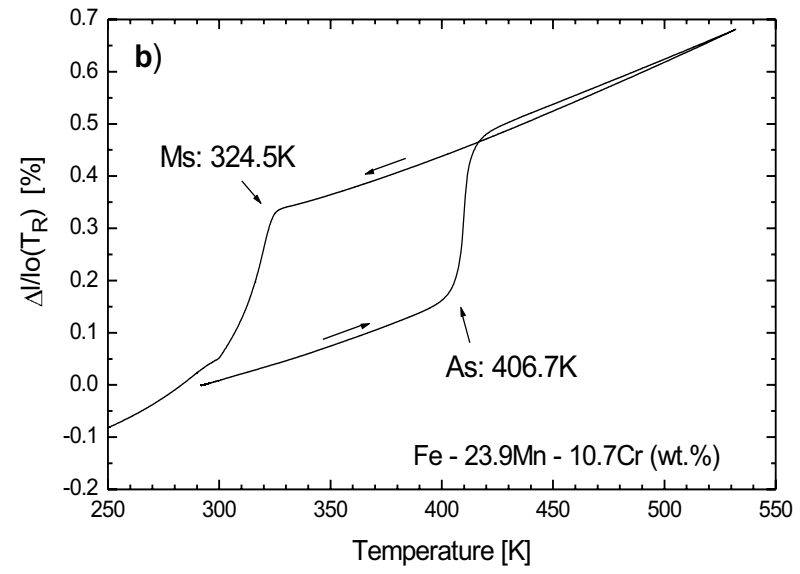

(b)

Fig. 1. Martensitic transformation temperatures measurements. The alloy composition is Fe-23.9Mn-10.7Cr (wt.\%). (a) Electrical resistivity measurement. (b) Dilatometry measurement.

An example of typical measurements is displayed in Fig. 1, where the first cycle is shown for Fe23.9Mn-10.7Cr (wt.\%) as measured by the electrical resistivity (Fig. 1a) and by dilatometry (Fig. 1b). The 
martensitic transformation is detected by means of dilatometry thanks to the large volume difference between fcc and hcp phases (around 2.5\%). The electrical resistivity measurements have also proven useful for determining MTTs due to the different electric properties of these phases. However, $\mathrm{A}_{\mathrm{s}}$ temperatures appeared somehow obscured in some electrical resistivity measurements, particularly after performing several thermal cycles.

The measured MTTs for the complete set of alloys under study are presented in Fig. 2a $\left(\mathrm{M}_{\mathrm{s}}\right.$ temperatures) and Fig. $2 \mathrm{~b}$ ( $\mathrm{A}_{\mathrm{s}}$ temperatures). The $\mathrm{x}$-axis of these figures corresponds to the Mn content of the alloy, while the $\mathrm{Cr}$ content is indicated in the y-axis. Each point in the graphs represents one alloy. The number next to each point indicates the corresponding measured transformation temperature, in $\mathrm{K}$.

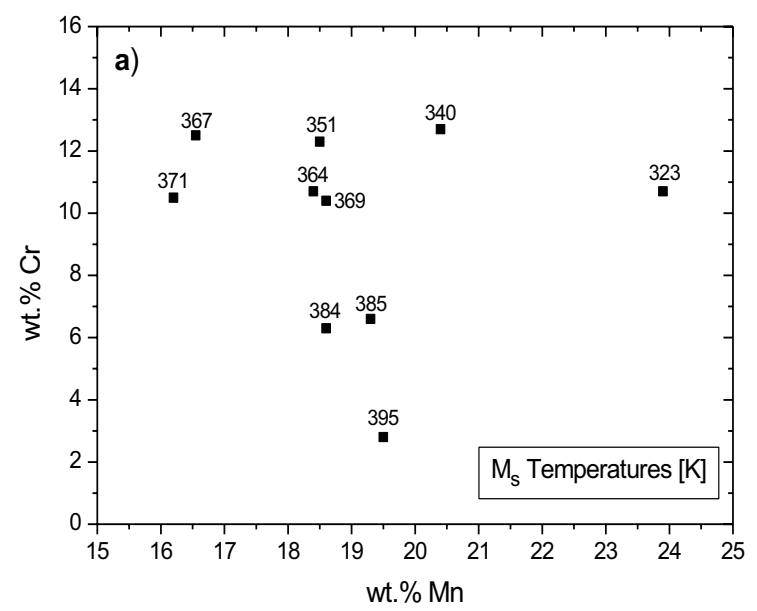

(a)

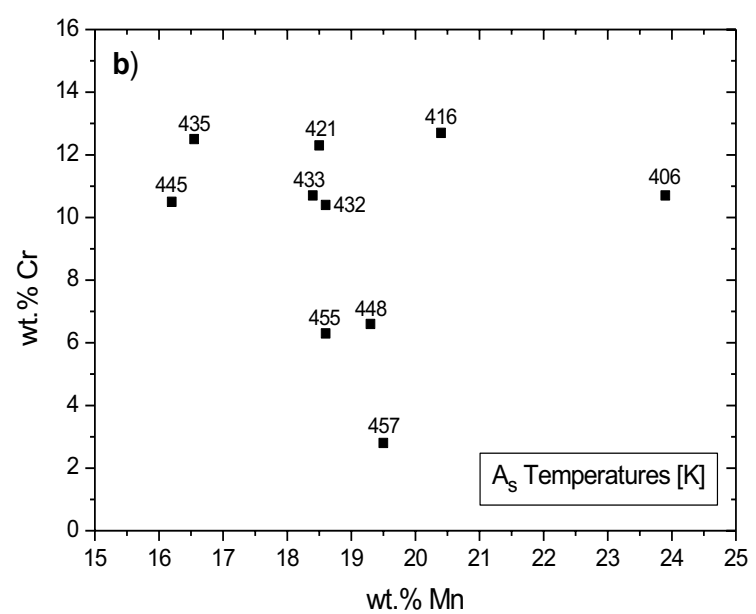

(b)

Fig. 2. Measured martensitic transformation temperatures for $\mathrm{FeMnCr}$ alloys. Each point represents one alloy. The number next to each point is the measured transformation temperature, in $K$. (a) $M_{s}$ temperatures. (b) $A_{s}$ temperatures.

\subsection{TEM observations}

TEM observations were performed to identify the main features of FeMnCr alloy microstructure. Fig. 3 shows a bright field image a Fe-23.9Mn-10.7Cr (wt. \%) alloy.

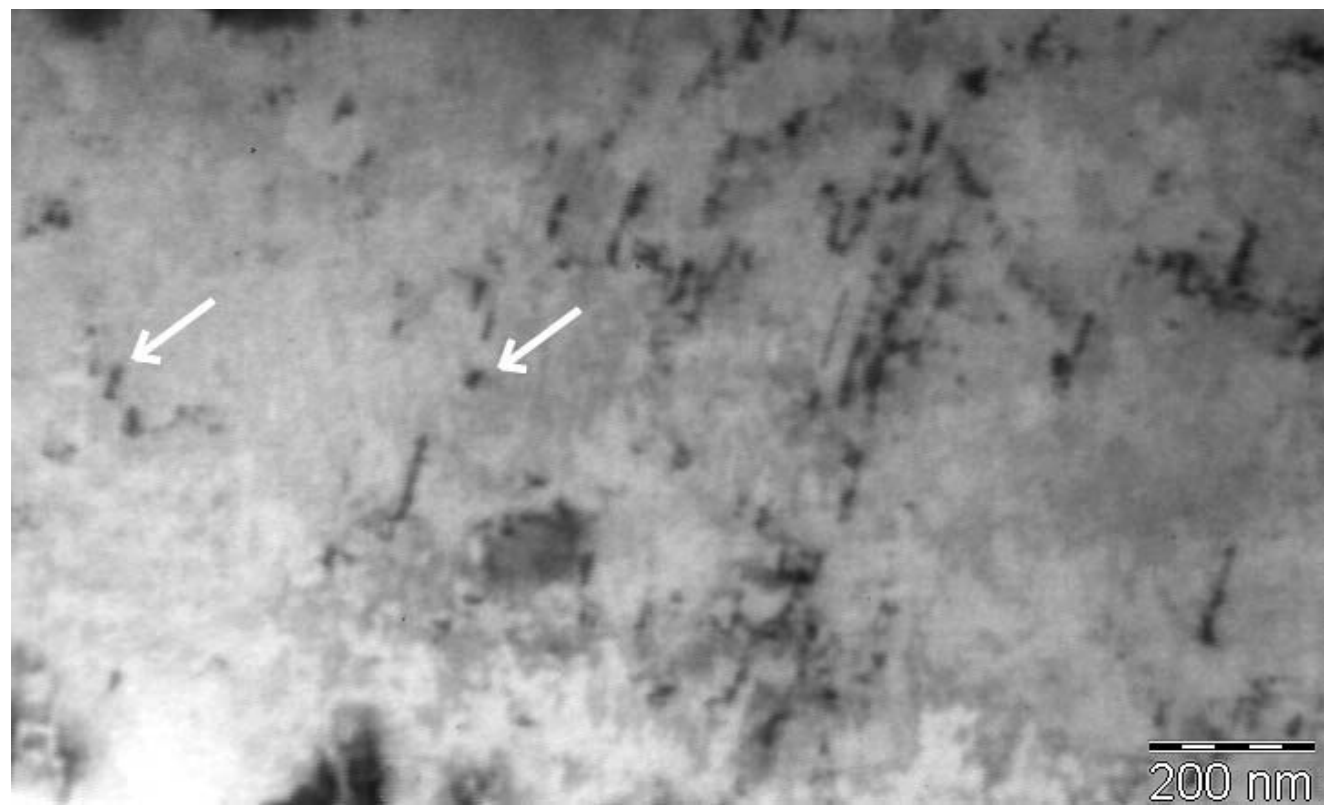

Fig. 3. Bright field TEM image of a Fe-23.9Mn-10.7Cr (wt. \%) sample. The matrix is fcc and the zone axis is close to [110 $]_{\mathrm{fcc}}$. Spots with the dark contrast, as those marked by arrows, correspond to precipitates. 
The zone axis in the figure is close to $[110]_{\mathrm{fcc}}$. The area appears nearly free from defects. Several spots with a dark contrast (as those marked by arrows in the figure) are observed. These spots were identified as precipitates. The average size of these precipitates is around $10 \mathrm{~nm}$. We were not able yet to measure the chemical composition of these precipitates due to their very small size. The precipitates loosely follow the traces of $(111)_{\text {fcc }}$ planes.

Fig. 4 shows another area of a similar sample. The figure is a dark field image which has been taken near the $[110]_{\text {fcc }}$ zone axis, using a martensite spot coinciding with a $111_{\text {fcc }}$ spot. As a result, thin martensite plates appear with the bright contrast in the image. Notably, most plates have a single orientation. This particular feature was observed in several areas of different similar samples. Precipitates appear to interact with martensite plates as seen, for example, in the zone marked by an arrow in the figure.

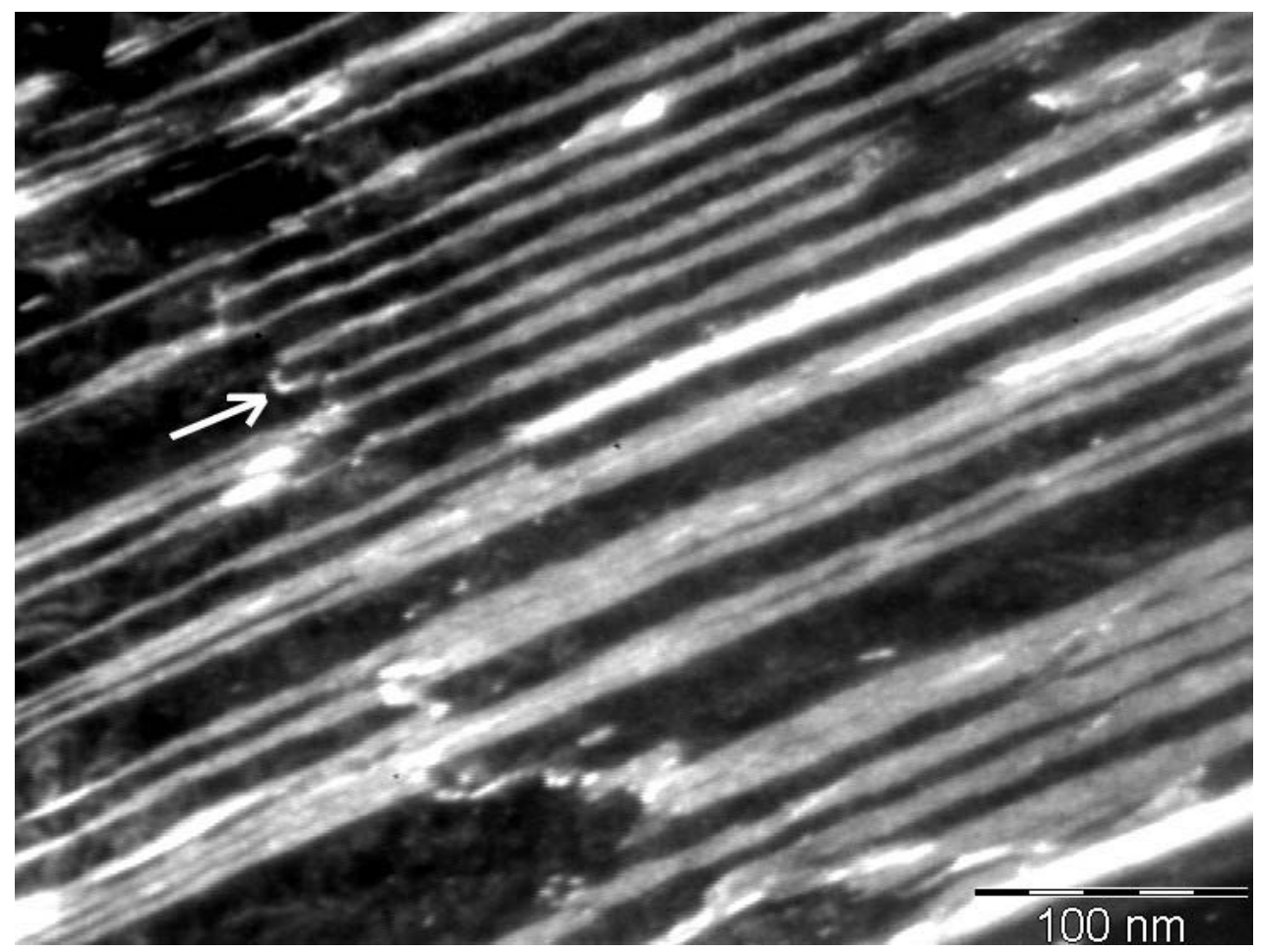

Fig. 4. Dark field TEM image of a Fe-23.9Mn-10.7Cr (wt. \%) sample. The matrix is fcc and the zone axis is close to [110] $]_{\text {fcc }}$ The image was taken using a martensite spot coinciding with a $111_{\mathrm{fcc}}$ spot. Thin, mono-oriented martensite plates appear with the bright contrast in the figure. Precipitates appear near the end of plates (see, for example, the zone marked by a white arrow).

\section{Discussion}

The metastable fcc/hcp martensitic transformation was detected in FeMnCr alloys, even in those cases containing a rather large amount of $\mathrm{Cr}$ (above $12 \mathrm{wt}$ \%), using both dilatometry and electrical resistivity. Fig. 1 shows that both techniques are suitable for MTTs measurements in this system.

Based on measured MTTs, we can conclude that Cr additions have the effect of stabilizing the fcc phase against hcp martensite. This relative stabilization is reflected in the steep decrease of MTTs as Cr contents increase (Fig. 2). For example, taking a line of approximately constant Mn content at 19 wt. \% in Fig. $2 \mathrm{a}$, the $\mathrm{M}_{\mathrm{s}}$ temperatures decrease from $395 \mathrm{~K}$ at about 2 wt. $\% \mathrm{Cr}$, to $351 \mathrm{~K}$ at about $12 \mathrm{wt}$ \% Cr. Similarly, $\mathrm{A}_{\mathrm{s}}$ temperatures decrease from $457 \mathrm{~K}$ to $421 \mathrm{~K}$ in the same composition interval. This austenite stabilizing effect of $\mathrm{Cr}$ is not unexpected, because it has been previously reported for higher order Fe-Mn-Si-Cr [8] and Fe-Mn-SiCr-Ni [11] alloys. Taking a constant Cr content, MTTs decrease as Mn content increase (Fig. 2). The effect is similar to what has been measured in the binary FeMn system [12] and several ternary systems [13, 14]. What is new here is that this tendency is verified even at $\mathrm{Cr}$ contents as high as $12 \mathrm{wt} \%$.

Hysteresis between $\mathrm{M}_{\mathrm{s}}$ and $\mathrm{A}_{\mathrm{s}}$ are of about $80 \mathrm{~K}$ in the $\mathrm{Fe}-\mathrm{Mn}-\mathrm{Cr}$ system, similar to what is found in the binary Fe-Mn system [12] and the ternaries containing Si [13] and Co [14]. This large hysteresis value is commonly explained by the large volume difference between the fcc and hcp phases and the absence of order in these structures.

TEM observations were mainly aimed at identifying the main characteristics of the alloys microstructure. Unexpectedly, we have found a large density of precipitates. We have observed them more or 
less equally distributed in the matrix and inside martensite plates (Fig. 3). In several cases, precipitates were aligned following the traces of stacking faults, that is along the traces of $(111)_{\text {fcc }}$ planes. We found no indications of the presence of precipitates in grain boundaries. As it was said in Section 3, the chemical composition of the precipitates could not be determined by the EDS technique due to their small size (about $10 \mathrm{~nm}$ ). Consulting the phase diagrams literature [15], and taking into account the annealing temperature applied to the alloys (1273 K), a reasonable guess is that the structure of these precipitates could be of the Cr-Mn $\sigma^{\prime}$ type. This structure is an ordered variation of the $\mathrm{Fe}-\mathrm{Cr} \sigma$ structure. In general, we have observed interaction between precipitates and the ends of martensite plates (Fig. 4). So, a hardening effect on the fcc matrix due to the presence of precipitates can be expected.

Another important feature is that martensite plates were observed to appear as single oriented variants in each grain. This observation is particularly interesting if we take into account that martensite was not stressinduced in these samples. The martensite present on the TEM picture was thermally induced because the $M_{s}$ of the alloy $(323 \mathrm{~K})$ was slightly above room temperature. This tendency to form mono-oriented variants could result in a good SME in these samples.

Further work is presently being directed to clarify the origin and structure of the precipitates, and to assess the mechanical and shape memory behaviour of Fe-Mn-Cr samples.

This work has been supported by ANPCyT under Grants 20144/04 and 02284/07, by Comisión Nacional de Energía Atómica and by Consejo Nacional de Investigaciones Científicas y Técnicas under Grant PIP 5657. The authors are grateful to Teresa Carrasco and Carlos Gómez Bastidas for their help with electrical resistivity measurements, thermal treatments and sample preparation. Enrique Aburto and Carlos Cotaro helped with the quartz encapsulation of samples, and with EDS composition analysis respectively.

\section{References}

[1] K. Enami, A. Nagasawa, S. Nenno, Scripta metall. 9, 941 (1975)

[2] A. Sato, E. Chishima, K. Soma, T. Mori, Acta metall. 30, 1177 (1982)

[3] A. Sato, E. Chishima, K. Soma, T. Mori, Acta metall. 32, 539 (1984)

[4] S. Kajiwara, Mat. Science Eng. A 273-275, 67 (1999)

[5] N. Bergeon, S. Kajiwara, T. Kikuchi, Acta mater. 48, 4053 (2000)

[6] H. Tanahashi, T. Maruyama, H. Kubo, Trans. Mat. Res. Soc. Jpn. 18B, 1149 (1994)

[7] Y. Watanabe, E. Miyazaki, H. Okada, Mat. Trans. 43, 974 (2002)

[8] H. Otsuka, H. Yamada, T. Maruyama, H. Tanahashi, S. Matsuda, M. Murakami, ISIJ Int. 30, 674 (1990)

[9] H. Otsuka, H. Yamada, H. Tanahashi, T. Maruyama, Mat. Sci. Forum 56-58, 655 (1990)

[10] O. A. Khomenko, I. F. Khil'kevich, G. Ye. Zvigintseva, Fiz. metal. metalloved. 37, 1325 (1974)

[11] J.C. Li, M. Zhao, Q. Jiang, Metall. Mat. Trans A 31, 581 (2000)

[12] S. M. Cotes, M. Sade and A. Fernández Guillermet, Metall. Mater. Trans. A, 26A (1995), 1957

[13] S. Cotes, A. Fernández Guillermet, M. Sade, J. Alloys Comp. 278 (1998), 231

[14] A. Baruj, A. Fernández Guillermet, M. Sade ; J. Phys. IV France, 7 (1997), C5-405

[15] M. Venkrataman, J.P. Neumann, Binary alloy phase diagrams (T. B. Massalski (Ed.) ASM, Metal Park, Ohio, USA, 1986), vol. 1, p. 833. 